\title{
2 TIPO CUKRINIO DIABETO NEMEDIKAMENTINIO GYDYMO BŪDAI IR JŲ POVEIKIS GLIKEMIJOS KONTROLEI
}

\author{
Kamilè Antanavičiūtė, Rūta Šarkūnaitė \\ Lietuvos sveikatos moksly universitetas, Medicinos akademija, Medicinos fakultetas
}

Raktažodžiai: veganiška dieta, vegetariška dieta, ketogeninè dieta, Viduržemio jūros dieta, fizinis aktyvumas, 2 tipo cukrinio diabeto kontrolè, HbA1c pokytis.

\section{Santrauka}

Tyrimo tikslas - atrinkti ir išanalizuoti populiarių dietu (augalinès - veganiškos ir vegetariškos; Viduržemio jūros; ketogeninès) bei fizinio aktyvumo poveikị mažinti glikemiją ir atsparumą insulinui pacientams, sergantiems 2 tipo cukriniu diabetu (CD). Poveikis ivvertintas remiantis $\mathrm{HbAlc}$ ir HOMA-IR rodiklių pokyčiais. Aptarti tinkamo fizinio aktyvumo rūšies pasirinkimo aspektai, esant skirtingoms 2 tipo CD komplikacijoms. Atliktoje sisteminejje literatūros apžvalgoje išanalizuoti 26 moksliniai straipsniai, kuriais remiantis galima teigti, jog didžiausias teigiamas nagrinètų mitybos būdų poveikis glikemijos kontrolei pastebetas laikantis Viduržemio jūros dietos, augalinè mityba daugiausia prisideda prie 2 tipo CD rizikos mažinimo, o fizinis aktyvumas daro teigiamą poveikị CD kontrolei tik tuomet, kai jis parinktas individualiai.

\section{Ivadas}

Pasaulio sveikatos organizacijos duomenimis, 2 tipo cukrinis diabetas (2 tipo CD) yra viena iš dažniausių lètinių ligu pasaulyje, pažeidžianti skirtingas organų sistemas bei stipriai paveikianti gyvenimo kokybę. Skaičiuojama, jog šiuo metu pasaulyje juo serga apie 463 milijonai 20-79 metų žmonių, o Lietuvoje sergančiųų skaičius siekia 5,4 proc. visos populiacijos [1]. Pagrindinis 2 tipo CD patogenezinis veiksnys yra didèjantis atsparumas insulinui, sukeliantis ilgalaikę hiperglikemiją, ilgainiui lemiantis kasos disfunkciją. Kol kasos funkcija nesutrikusi, sergant 2 tipo $\mathrm{CD}$, insulino kiekis nèra sumažejęs, todèl šis diabeto tipas dar vadinamas nuo insulino kiekio nepriklausomu diabetu [2]. Dėl šios priežasties 2 tipo CD gydymo metodai neapsiriboja tik dirbtinio insulino injekcijomis ar peroraliniais hipoglikuojančiais vaistais. Labai svarbus ir nemedikamentinis gydymas dieta bei fizine veikla [3]. Anksčiau 2 tipo CD kontrolè buvo siejama su žemo glikeminio indekso produktų dieta, tačiau vis daugiau aprašomi ir kiti mitybos būdai, stabilizuojantys šios ligos eigą. Literatūroje vis dažniau nagrinejjamas įvairių sporto rūšiu poveikis. Dietų bei fizinès veiklos efektyvumui vertinti naudojami glikuoto hemoglobino ( $\mathrm{HbA} 1 \mathrm{c})$, atspindinčio vidutinę 3 mènesių glikemiją, bei HOMA-IR (angl. Homeostatic model assessment and insulin resistance) indekso, nurodančio atsparumą insulinui, pokyčiai. Nustatyta, jog HbA1c sumažejus 1 proc., miokardo infarkto rizika sumažeja 14 proc., o mirtingumo nuo diabeto komplikacijų rizika sumažejja net 20 proc., todèl šis rodiklis yra labai naudingas, vertinant 2 tipo CD kontrolę [4].

Darbo tikslas - atrinkti ir išanalizuoti 2 tipo cukrinio diabeto nemedikamentinio gydymo būdus ir jų poveiki glikemijos kontrolei.

\section{Tyrimo medžiaga ir metodai}

Atlikta detali sisteminé mokslinės literatūros apžvalga ir analizè internetinèse mokslinių darbų bazèse PubMed, ScienceDirect, UpToDate, Cohrane Library. Literatūra atrinkta naudojant raktinius žodžius: veganiška, vegetariška dieta, ketogeninè dieta, Viduržemio jūros dieta, fizinis aktyvumas, 2 tipo cukrinio diabeto kontrolè. Atrinkti ir analizuoti 2014-2020 metais anglų kalba išspausdinti 26 moksliniai straipsniai, kuriuose pateikiami klinikiniai tyrimai, atsitiktinių imčių tyrimai ir stebejimo duomenys, nagrinèjantys skirtingų mitybos režimų ir fizinio aktyvumo ịtaką glikemijos kontrolei pagal HbA1c pokytị.

\section{Tyrimo rezultatai}

Viduržemio jūros dieta kilusi iš Viduržemio jūros regiono, kurios pagrindą sudaro daržovès, vaisiai, riešutai, mažai apdoroti grūdiniai produktai, tyras alyvuogių aliejus, vištiena, jūros gèrybès bei 1-2 raudonojo vyno taurès per dieną. Laikantis šios mitybos, žymiai sumažinamas raudonos mėsos, cukraus ir gyvūninès kilmės produktų kiekis. Ši mityba gausi mononesočiųjų riebalų rūgščių, todèl vis dažniau 
rekomenduojama širdies ir kraujagyslių ligomis sergantiems pacientams. Ši mityba pasižymi gausiu vitaminų, mineralų, skaidulų ir antioksidantų kiekiu bei lanksčiomis taisyklèmis, todèl teigiamai veikia visą organizmą, o jos principų galima laikytis visą gyvenimą. Dèl šios priežasties Viduržemio jūros mitybos nauda pastebima ir sergant 2 tipo CD. Atliktuose tyrimuose nustatytas žymus HbA1c sumažejimas $(0,1-0,6$ $\%$ ), pastebètas teigiamas KMI, liemens, klubų apimties, trigliceridų kiekio pokytis. Nustatyta, jog ši dieta naudingesnè mažinant $\mathrm{HbA1c}$, negu mažai angliavandenių turinti dieta ar veganinè mityba, tačiau, jos laikantis, svarbu neviršyti nustatyto individualaus paros kalorijų kiekio [5-8].

Vegetariška ir veganiška mityba. Šios mitybos nauda nagrinejjama jau ne vieną dešimtmeti, tačiau jos efektas vis dar vertinamas dviprasmiškai. Vegetariška mityba skirstoma ị lakto-ovo vegetarizmą (nevalgoma mèsos, žuvies, tačiau valgomi pieno produktai ir kiaušiniai) ir peskovegetarizmą (kai nevalgoma mėsos, pieno produktų ir kiaušinių, bet valgoma žuvies). Veganiškos mitybos principas yra visiškas gyvūninės kilmės produktų atsisakymas. Vieni literatūros šaltiniai nurodo, jog augalinė mityba prisideda prie širdies ir kraujagyslių ligų, nutukimo, 2 tipo CD ar lètinių uždegimų gydymo bei reikšmingai mažina mirtingumą. Pagrindinis šios mitybos veikimo mechanizmas yra gyvūninių baltymų - medžiagų, didinančių atsparumą insulinui, atsisakymas $[9,10]$. Šị teiginị patvirtina ịvairūs tyrimai, kuriuose rasta, jog 2 tipo CD dažnis veganų bei vegetarų populiacijose yra reikšmingai mažesnis, nei visavalgių populiacijoje. Nors laikantis augalinès mitybos principų gyvūniniai baltymai pakeičiami augaliniais ir gerokai padidèja suvartojamų angliavandenių kiekis, nustatyta, jog taikant šias dietas, pasiektas žymus HbA1c $(0,4-0,5 \%)$, svorio bei liemens apimties sumažèjimas. Be to, naudojant HOMA-IR indeksą, nustatytas didesnis jautrumas insulinui [9,11-15]. 2019 metais mokslininko J. Salas-Salvado ir kitų Ispanijoje atliktoje literatūros apžvalgoje aprašytas Adventist Health Study - 2 tyrimas, kuriame nustatyta atvirkštinè koreliacija tarp gyvūninių produktų kiekio mityboje ir 2 tipo CD išsivystymo rizikos: kuo didesnis augalinių produktų kiekis mityboje, tuo mažesnè rizika susirgti 2 tipo CD. Nustatyti šansų santykiai (ŠS 95\% pasikliautinasis intervalas) susirgti 2 tipo $\mathrm{CD}$ : veganu grupèje $\breve{S} S=0,51(0,40-0,66)$, lakto-ovo vegetarų $\breve{S} S=0,54(0,49$ $-0,60)$, peskovegetarų $\breve{S} S=0,70(0,61-0,80)$. Didžiausia nauda, laikantis augalinès mitybos, buvo pasiekta vartojant mažai perdirbtus, visagrūdžius produktus, galimai dèl žemo šių produktų glikeminio indekso [11]. Dèl šios priežasties dalis šaltinių nepripažįsta šios mitybos efektyvumo kontroliuojant 2 tipo $C D$, tačiau neatmeta galimybès, jog ši mityba padeda jo išvengti $[12,16,17]$. Vegetarai ir veganai dažnai pasižymi mažu B12 vitamino kiekiu, o gydymas metforminu dar labiau mažina jo kiekị organizme, todèl, pasirinkus šią mitybą sergant 2 tipo $\mathrm{CD}$ ir vartojant metforminą, būtina periodinè B12 vitamino kontrolè [15].

Ketogenine dieta. Pastaraisiais metais staiga išpopuliarejjusi ketogeninè dieta paremta tuo, jog mityboje didžiausią dalį sudaro riebalai, o iš nekrakmolingų daržovių gaunamų angliavandenių kiekis sumažinamas iki 20-50 g per dieną. Ši dieta išpopuliarèjo dèl ypač greito svorio kritimo bei ilgesnio sotumo jausmo, sukelto išsiskyrusių ketonų. Dėl suvartojamo labai mažo angliavandenių kiekio, organizmui sukeliamas bado režimas - ketozè. Ketozè - tai metabolinè būklè, kai pagrindinis energijos šaltinis yra ketonai, susidarę iš organizme esančių riebalų rūgščių $[5,18]$. Remiantis šios dietos mechanizmu, ketogeninè dieta turètų būti labai naudinga sergantiems 2 tipo CD: dèl sumažejusio angliavandenių kiekio mažeja insulino išsiskyrimas ir kartu dideja jautrumas insulinui. Tačiau radikaliai pakeitus angliavandenių kiekị maiste ir kartu vartojant insuliną ar sulfonamidų preparatus (gliklazidas, glipizidas), dideja hipoglikemijos rizika. Atliktuose tyrimuose stebimas žymus HbA1c $(0,17-0,32 \%)$ bei HOMA-IR indekso sumažejimas, lyginant su prieš dietą buvusiais rodikliais. Būtina aptarti ir šalutinius šios mitybos efektus: dèl sumažèjusio vaisių ir daržovių suvartojimo atsiranda skaidulų, vitaminų ir mineralų stoka, pasireiškianti vidurių užkietejimu, vadinamuoju keto gripu, kurio simptomai primena gripo simptomus. Nors ši mityba neriboja kalorijų kiekio, tačiau stipriai apribotas angliavandenių bei didelis riebalų kiekis ilgainiui gali sukelti dislipidemiją ar šrdies ir kraujagyslių ligas [17,19-21].

Fizinis aktyvumas. Judejjimas yra labai svarbi sveiko gyvenimo būdo sudedamoji dalis, tačiau pasaulyje vis daugiau žmonių didžiają dienos dalị praleidžia sèdėdami. Šis veiksnys sukelia svorio didejjimą, didina širdies ir kraujagyslių bei 2 tipo CD dažnį. Atlikti tyrimai rodo, jog sergant 2 tipo $\mathrm{CD}$, fizinis aktyvumas mažina atsparumą insulinui, $\mathrm{HbA} 1 \mathrm{c}$, arterini kraujo spaudimą, gerina lipidogramos rezultatus [22]. Šis poveikis stebimas dèl mažejančio visceralinių ir pilvo srities riebalų kiekio, o kartu ir jų išskiriamų citokinų ir adiponektino, skatinančio atsparumą insulinui. Šis poveikis išlieka net iki 72 valandų po paskutinio fizinio krūvio [23]. Sergant 2 tipo CD, rekomenduojami aerobiniai (bėgimas, ejjimas, plaukimas ir pan.), jègos stiprinimo (pratimai su svoriais, pasipriešinimo gumomis, savo kūno svoriu) bei kombinuoti (aerobiniai ir jègos stiprinimo) pratimai. Ryškiausias glikuoto hemoglobino sumažejjimas stebètas užsiimant kombinuotais pratimais. Jų metu stebėtas mažesnis hipoglikemijų dažnis bei stabilesnis gliukozès kiekis kraujyje, negu kitų treniruočių metu [24-26]. Tyrimai, nagrinejjantys fizinio aktyvumo poveiki jautrumui insulinui, nurodo, jog HOMA-IR indekso rezultatai neigiamai kore- 
liuoja su vaikščiojimo trukme - kuo daugiau sergantysis vaikšto, tuo rezistentiškumas mažesnis [22].

Nustatyta, jog fizinis aktyvumas nutolina diabeto komplikacijų pasireiškimą, o joms išsivysčius - slopina komplikacijų progresavimą. Esant komplikuotai ligai, fizinį aktyvumą turi paskirti profesionalūs specialistai. Esant diabetinei retinopatijai, nepatartinos aukšto intensyvumo aerobinès bei jègos stiprinimo treniruotès dèl padidejusios hemoftalmo rizikos [23]. Sportas sergant diabetine nefropatija gali padidinti albumino kiekị šlapime, tačiau šiuo atveju jègos stiprinimo pratimai galimai gerina glomerulų filtracijos greitį, todèl yra rekomenduojami. Kita 2 tipo CD komplikacija - diabetinė neuropatija. Jos metu susilpnèja jutimai rankose ir kojose, todèl šiems pacientams sunku judèti. Šiuo atveju neuropatijos simptomatikai sumažinti rekomenduojami Thai Chi bei vidutinio intensyvumo aerobiniai pratimai. Šių treniruočiu metu gerẻja sergančiųjų pusiausvyra, laikysena bei mažèja griuvimo rizika [23]. Būtina pabrěžti, jog esant diabetinei neuropatijai, turi būti užtikrinta tinkama pèdų bei avalynès priežiūra, vengiant sunkesnių komplikacijų, tokių kaip diabetinè pèda.

Remiantis Amerikos diabeto asociacijos rekomendacijomis, suaugusiems, sergantiems 2 tipo $\mathrm{CD}$, rekomenduojamos bent trys 50 minučių trukmès vidutinio ar sunkaus intensyvumo aerobinès bei trys 25 minučiu trukmès jègos stiprinimo treniruotès per savaitę su dviem poilsio dienomis. Dẻl sergančiujų 2 tipo CD nutukimo, jiems dažnai sunku pasiekti reikiamą aerobinių treniruočių efektyvumą, todèl, siekiant geriausio glikemijos kontrolès rezultato, siūloma ilginti jëgos treniruotes [26,27].

\section{Rezultatų aptarimas}

Apibendrinant nemedikamentinio gydymo galimybes, visos minètos dietos prisideda prie 2 tipo CD kontrolès gerinimo, tačiau didžiausia nauda pastebèta laikantis Viduržemio jūros dietos. Šios dietos principus lengviausia pritaikyti kasdienejje praktikoje, tačiau būtina stebèti suvartojamų kalorijų ir alkoholio kiekị. Nors stebimas ir ketogeninès dietos efektyvumas, koreguojant glikemiją, tačiau kol kas teigiamas poveikis pastebetas šią mitybą taikant trumpą laikotarpi 3-4 mènesius. Ilgainiui mikroelementų trūkumas bei širdies ir kraujagyslių ligų rizika nusveria minètą naudą. Yra pakankamai ịrodymų, jog fizinis aktyvumas gerokai pagerina 2 tipo CD sergančiujų gyvenimo kokybę, tačiau renkantis treniruotes, reikia labai profesionaliai parinkti jų intensyvumą bei trukmę, atsižvelgiant ị individualius sergančiojo poreikius, derinant šị nemedikamentinị gydymą su kitais gydymo būdais [28].

\section{Išvados}

1. Vertinant mitybos tipus pagal HbAlc pokytị, didžiausias teigiamas poveikis glikemijos kontrolei pastebètas laikantis Viduržemio jūros dietos.

2. Taikant augalinę mitybą, didžiausios naudos pasiekta vartojant mažai perdirbtus, viso grūdo produktus.

3. Kol kas nèra bendros nuomonès, jog augalinè mityba lemia gerą glikemijos kontrolę, tačiau nustatyta, jog ši mityba padeda išvengti 2 tipo $\mathrm{CD}$.

4. Teigiamas ketogeninès mitybos poveikis sergant 2 tipo $\mathrm{CD}$, stebimas šią mitybą taikant tik trumpą laikotarpi -3-4 mènesius.

5. Tik individualiai pritaikytas fizinis aktyvumas turi teigiamą poveikị CD kontrolei.

\section{Literatūra}

1. World Health Organization.

https://www.who.int/news-room/fact-sheets/detail/diabetes

2. International Diabetes Federation.

https://www.idf.org/aboutdiabetes/type-2-diabetes.html

3. Lee Y, Kim S, Lee I, Kim J, Park K, Jeong J et al. Effect of a brown rice based vegan diet and conventional diabetic diet on glycemic control of patients with type 2 diabetes: a 12-week randomized clinical trial. PLoS ONE 2016;11(6):e0155918. https://doi.org/10.1371/journal.pone.0155918

4. Amanat S, Ghahri S, Dianatinasab A, Fararouei M, Dianatinasab M. Exercise and type 2 diabetes. Physical Exercise for Human Health 2020;91-105.

https://doi.org/10.1007/978-981-15-1792-1_6

5. Chester B, Babu J, Greene M, Geetha T. The effects of popular diets on type 2 diabetes management. Diabetes/Metabolism Research and Reviews 2019;35(8).

https://doi.org/10.1002/dmrr.3188

6. Georgoulis M, Kontogianni M, Yiannakouris N. Mediterranean diet and diabetes: prevention and treatment. Nutrients 2014;6(4):1406-1423.

https://doi.org/10.3390/nu6041406

7. Tuttolomondo A, Simonetta I, Daidone M, Mogavero A, Ortello A, Pinto A. Metabolic and vascular effect of the mediterranean diet. International Journal of Molecular Sciences 2019;20(19):4716.

https://doi.org/10.3390/ijms20194716

8. Alcubierre N, Granado-Casas M, Real J, Perpiñán H, Rubinat E, Falguera M et al. Spanish People with Type 2 Diabetes Show an Improved Adherence to the Mediterranean Diet Nutrients 2020;12(2):560.

https://doi.org/10.3390/nu12020560

9. McMacken M, Shah S. A plan-based diet for the prevention and treatment of type 2 diabetes. Journal of Geriatric Cardiology 2017;14(5):342-354.

10. Adeva-Andany M, Rañal-Muíño E, Vila-Altesor M, FernándezFernández C, Funcasta-Calderón R, Castro-Quintela E. Dietary habits contribute to define the risk of type 2 diabetes in humans. 
Clinical Nutrition ESPEN 2019;34:8-17.

https://doi.org/10.1016/j.clnesp.2019.08.002

11. Salas-Salvadó J, Becerra-Tomás N, Papandreou C, Bulló M. Dietary patterns emphasizing the consumption of plant foods in the management of type 2 diabetes: a narrative review. Advances in Nutrition 2019;10(Supplement_4):S320-S331. https://doi.org/10.1093/advances/nmy102

12. Mihrshahi S, Ding D, Gale J, Allman-Farinelli M, Banks E, Bauman A. Vegetarian diet and all-cause mortality: evidence from a large population-based Australian cohort - the 45 and up study. Preventive Medicine 2017;97:1-7.

https://doi.org/10.1016/j.ypmed.2016.12.044

13. Chen Z, Zuurmond M, van der Schaft N, Nano J, Wijnhoven $\mathrm{H}$, Ikram $\mathrm{M}$ et al. Plant versus animal based diets and insulin resistance, prediabetes and type 2 diabetes: the Rotterdam study. European Journal of Epidemiology 2018;33(9):883-893. https://doi.org/10.1007/s10654-018-0414-8

14. Toumpanakis A, Turnbull T, Alba-Barba I. Effectiveness of plant-based diets in promoting well-being in the management of type 2 diabetes: a systematic review. BMJ Open Diabetes Research \& Care 2018;6(1):e000534.

https://doi.org/10.1136/bmjdrc-2018-000534

15. Pawlak R. Vegetarian diets in the prevention and management of diabetes and its complications. Diabetes Spectrum 2017;30(2):82-88.

https://doi.org/10.2337/ds16-0057

16. Lee Y, Kim S, Lee I, Kim J, Park K, Jeong J et al. Effect of a brown rice based vegan diet and conventional diabetic diet on glycemic control of patients with type 2 diabetes: a 12-week randomized clinical trial. PLoS ONE 2016;11(6):e0155918. https://doi.org/10.1371/journal.pone.0155918

17. Kahleova H, Tura A, Klementova M, Thieme L, Haluzik M, Pavlovicova R et al. A plant-based meal stimulates incretin and insulin secretion more than an energy- and macronutrient-matched standard meal in type 2 diabetes: a randomized crossover study. Nutrients 2019;11(3):486.

https://doi.org/10.3390/nu11030486

18. Hamdy O, Tasabehji M, Elseaidy T, Tomah S, Ashrafzadeh S, Mottalib A. Fat versus carbohydrate-based energy-restricted diets for weight loss in patients with type 2 diabetes. Current Diabetes Reports 2018;18(12).

https://doi.org/10.1007/s11892-018-1103-4

19. Ludwig D. The ketogenic diet: evidence for optimism but high-quality research needed. The Journal of Nutrition 2019; https://doi.org/10.1093/jn/nxz308

20. Churuangsuk C, Lean M, Combet E. Low and reduced carbohydrate diets: challenges and opportunities for type 2 diabetes management and prevention. Proceedings of the Nutrition Society 2020;1-16. https://doi.org/10.1017/S0029665120000105

21. Walton C, Perry K, Hart R, Berry S, Bikman B. Improvement in glycemic and lipid profiles in type 2 diabetics with a 90-day ketogenic diet. Journal of Diabetes Research 2019;2019:1-6. https://doi.org/10.1155/2019/8681959

22. Li L, Yin X, Yu D, Li H. Impact of physical activity on glycemic control and insulin resistance: a study of community-dwelling diabetic patients in Eastern China. Internal Medicine 2016;55(9):1055-1060.

https://doi.org/10.2169/internalmedicine.55.4943

23. Amanat S, Ghahri S, Dianatinasab A, Fararouei M, Dianatinasab M. Exercise and type 2 diabetes. Physical Exercise for Human Health 2020;91-105.

https://doi.org/10.1007/978-981-15-1792-1_6

24. Lee J, Kim D, Kim C. Resistance training for glycemic control, muscular strength, and lean body mass in old type 2 diabetic patients: a meta-analysis. Diabetes Therapy 2017;8(3):459-473. https://doi.org/10.1007/s13300-017-0258-3

25. AminiLari Z, Fararouei M, Amanat S, Sinaei E, Dianatinasab S, AminiLari $\mathrm{M}$ et al. The effect of 12 weeks aerobic, resistance, and combined exercises on omentin-1 levels and insulin resistance among type 2 diabetic middle-aged women. Diabetes Metabolism Journal 2017;41(3):205.

https://doi.org/10.4093/dmj.2017.41.3.205

26. Armstrong M, Sigal R. Exercise as medicine: key concepts in discussing physical activity with patients who have type 2 diabetes. Canadian Journal of Diabetes 2015;39:S129-S133. https://doi.org/10.1016/j.jcjd.2015.09.081

27. Lifestyle management:standards of medical care in diabetes-2018. Diabetes Care 2017;41(Supplement 1):S38-S50. https://doi.org/10.2337/dc18-S004

28. Cai H, Li G, Zhang P, Xu D, Chen L. Effect of exercise on the quality of life in type 2 diabetes mellitus: a systematic review. Quality of Life Researc. 2016;26(3):515-530.

https://doi.org/10.1007/s11136-016-1481-5

\section{NON - PHARMACOLOGICAL MANAGEMENT OF TYPE 2 DIABETES AND THEIR IMPACT ON GLYCEMIC CONTROL \\ K. Antanavičiūtė, R. Šarkūnaitė}

Keywords: vegan diet, vegetarian diet, ketogenic diet, mediterraean diet, physical activity, type 2 Diabetes managment, HbA1c change.

Summary

The aim of this study was to systematize and analyze the data about several popular diets (plant-based (veganism, vegetarianism), mediterranean, ketogenic diets) and physical activity effect on glycemia and insulin resistance for patients with type 2 Diabetes (T2DM). This effect was evaluated based on HbA1c and HOMA - IR value differences. Furthermore, we debated different aspects of choosing the correct type of physical activity based on complications of T2DM. This systematic review analyzes 26 full-text articles, presented in English. According to our findings, mediterranean diet showed the greatest positive effect on $\mathrm{HbA} 1 \mathrm{c}$, the most effective diet to reduce the risk of type 2 diabetes was plant - based diet, while physical activity leads to good illness control only when the type of activity was chosen individually.

Correspondence to: kamile.antanaviciute@gmail.com

Gauta 2021-05-05 